\title{
ALMA E DESTINO DO POVO PORTUGUÊS. O FADO COMO IDENTIDADE NACIONAL LUSA NO LIMIAR DO ESTADO NOVO $(1927$ - 1933)
}

\author{
PORTUGUESE PEOPLE'S SOUL AND DESTINY. THE FADO AS \\ LUSITANIAN NATIONAL IDENTITY ON THE THRESHOLD OF THE \\ ESTADO NOVO $(1927-1933)$
}

\author{
Lucas André Gasparotto \\ Mestrando em História - PUCRS \\ E-mail: lucas.gasparotto@gmail.com
}

\begin{abstract}
RESUMO: o fado, gênero musical considerado canção nacional em Portugal, apresenta trajetória histórica cuja origem remonta ao início da segunda metade do século XIX. Desde pelo menos o último terço dos oitocentos, observa-se, nas primeiras obras dedicadas à história do fado, o aparecimento de um debate acerca do status de símbolo nacional atribuído ao gênero. É, contudo, no final dos anos 1920 e início dos 1930 que se observa uma série de elementos responsáveis por atribuir carga simbólica e identitária ao fado, capaz de consolidá-lo como identidade nacional portuguesa. Através de conjunto de fontes que contempla legislação, obras literárias e jornalísticas e jornais de temática específica, este trabalho analisa as características do cenário musical fadista em Portugal durante o período de 1927 a 1933, destacando um processo de ritualização das práticas artísticas que objetivava dignificar o gênero mediante às diversas camadas da sociedade. A pesquisa sustenta-se na discussão em torno dos conceitos de nação e identidade nacional, a fim de definir o fado como alma e destino do povo português, enquanto canção popular com status de canção nacional capaz de credenciá-lo como uma cultura comum.
\end{abstract}

Palavras-chave: Fado. Nação. Identidade nacional.

ABSTRACT: The Fado is musical style that is considered the national song in Portugal. It has a historical path that dates back to the second half of the nineteenth century. Since the last third of the nineteenth century it can be seen, in the first works devoted to the history of Fado, the emergence of a debate around the national symbol status assigned to this musical style. However, it is only in the late 1920s and the early 1930s that it is possible to identify a variety of factors that is responsible for assigning symbolic and identity aspects to the Fado, enabling its consolidation as a Portuguese national identity. By research of a set of data that includes legislation, literary and journalistic studies and specific journals, this work analyzes the characteristics of the Fado music style scene that takes place through 1927 to 1933. It highlights a ritualization process of artistic practices that was aimed to dignify the music style between the various strata of Portuguese society. Furthermore, this research rests on the debate around the concepts of nation and national identity in order to define the Fado as Portuguese people's soul and destiny, while popular song with national status, that qualifies as a common culture.

Keywords: Fado. Nation. National identity. 


\section{Apresentação 1}

Em um trabalho anterior sobre o fado ${ }^{2}$, destacou-se o que se denominou de uma inquietação inicial de pesquisa. Naquele momento constatara-se que o gênero musical em questão, não obstante considerado símbolo da nacionalidade lusa, não figurava entre as obras clássicas dedicadas ao estudo da cultura em Portugal por historiadores renomados no século XX. A razão para a existência da lacuna historiográfica foi, então, atribuída a questões políticas ligadas ao Estado Novo - o fado fora considerado salazarista após a Revolução de 1974 -, bem como revelou a ausência de consenso com relação ao status de canção nacional atribuído ao fado ao longo dos anos.

De lá pra cá, o desenvolvimento da pesquisa não só reforçou aquelas constatações, como salientou a estreita relação entre o fado e uma espécie de comportamento atribuído aos portugueses. Essa vinculação possui força suficiente para atravessar o século XX. Nos primeiros anos, as obras de Pinto de Carvalho (1983), de 1903, e de Alberto Pimentel (1904), de 1904, dedicadas a escrever histórias do fado, são ilustrativas. Na primeira, o autor vaticina que "o fado subsistirá, porque ele corresponde maravilhosamente à nossa índole contemplativa, elegíaca e sonhadora, porque ele reflete nossa alma ondeante, e diversa como o homem de Montaigne" (1983, p. 288, grifos do autor); na segunda, o autor extrapola o vaticínio lançado por Carvalho (1983) ao afirmar, endossando as ponderações do erudito português Rocha Peixoto, que

o fado [...] e o que n'ele se diz de sonho, de amor, de ciume, de ausencia, de saudade e principalmente de conformação com o cru e negro imperio do destino, eis o que exprime dramaticamente a feição da alma nacional. $O$ fado é portuguez, é toda uma mentalidade, é toda uma Historia (PIMENTEL, 1904, pp. 14-15).

Em análises de renomados historiadores contemporâneos dedicados a discutir a cultura em Portugal, a referida relação encontra sustentação na obra de António José Saraiva (1994),

1 O presente artigo tem origem em trabalho apresentado no IX Congresso Internacional de Estudos IberoAmericanos - IX CIEIA, realizado na Pontifícia Universidade Católica do Rio Grande do Sul (PUCRS), Porto Alegre, em outubro de 2013. Trata-se de versão modificada do referido trabalho, sobretudo, na segunda parte, e expõe resultados de pesquisa desenvolvida junto ao Programa de Pós-Graduação em História da PUCRS.

${ }^{2}$ GASPAROTTO, [no prelo]. 
concluída em 1980, a respeito de "algumas feições persistentes da personalidade cultural portuguesa" (1994, p. 75): "seria também de notar o culto da dor [...]. O fado é a expressão mais popular deste 'gosto de ser triste': é um lamento entrecortado de soluços” (1994, p. 86). Mais de quinze anos depois, em 1997, era a vez de Eduardo Lourenço (1999) relacionar o fado à "percepção [pelos portugueses] da vida e do destino como essencialmente 'trágico"” (1999, p. 43). Também nas páginas do jornal Guitarra de Portugal é possível constatar a referida relação através, principalmente, do uso das expressões alma e destino; por se tratar da principal fonte utilizada neste trabalho, tratar-se-á de seu conteúdo ao longo do texto.

Ante a este estado de coisas, quer se reafirmar, neste artigo, a necessidade de abordar a perspectiva, já utilizada no referido trabalho anterior, de um futuro projetado desde o presente (KOSELLECK, 2006), a qual se sustenta numa visão do fado herdeira da tradição romântica (HERDER, 1959; FICHTE, 2009), como alma e destino do povo português, enquanto música popular considerada canção nacional, e, portanto, símbolo identitário. Desde essa perspectiva, este trabalho analisa elementos que tornaram possível a consolidação do fado como cultura comum capaz de credenciá-lo como identidade nacional. Aborda-se, para tanto, as modificações no meio e na poesia fadista de 1927 a 1933, período no qual se observam medidas de ordenamento inseridas na lógica nacionalista a que o país foi submetido no momento imediatamente anterior à promulgação da Constituição de 1933, a qual marca a institucionalização do Estado Novo em Portugal (1933-1974).

$\mathrm{O}$ artigo divide-se em duas partes. Na primeira, a fim de explicitar o recorte temporal, apresenta-se o contexto de instabilidade política que marcou a Primeira República portuguesa e o ordenamento nacionalista característico do limiar do Estado Novo, sobretudo a partir da publicação do Decreto ${ }^{\circ}$ 13.564, de 6 de maio de 1927, durante a ditadura militar dos anos 1926-1928; em seguida, a história do Fado é abordada desde o seu surgimento como gênero degenerado até a consagração como canção nacional. Na segunda parte, a discussão teórica é realizada em torno dos conceitos de nação e identidade nacional, sustentada naquela perspectiva anteriormente mencionada. 


\section{O limiar do Estado Novo e as modificações no Fado}

\subsection{Instabilidade política e ordenamento nacionalista}

O recorte temporal estabelecido neste trabalho é demarcado pela publicação, em Portugal, de dois dispositivos legais. O Decreto $\mathrm{n}^{\mathrm{o}} 13.564$, de 6 de maio de 1927, e a promulgação da Constituição Política da República Portuguesa, a 22 de fevereiro de 1933 $\left(\right.$ PORTUGAL, 1933) ${ }^{3}$, a qual visava a organizar o estado por meio de corporações, entre as quais, as culturais, "visando objetivos científicos, literários, artísticos ou de educação física" (MARQUES, 1991, p. 150). O decreto em questão promulgou disposições legais de mais freqüente aplicação relativas a espectáculos públicos (PORTUGAL, 1927, p. 689), o qual, entre outras disposições, estabeleceu a concessão de licenças profissionais aos artistas (Art. $\left.4^{\circ}, n^{\circ} .4\right)$. A efetiva aplicação dessa norma pode ser verificada através da licença profissional concedida a Sebastião Caetano Pires em 1939, onde se lê: "licença para o exercício da profissão de 'Cantador de fados' passada nos termos do Decreto $\mathrm{n}^{\circ}$. 13.564, de 6 de Maio de $1927^{\prime \prime 4}$.

Os anos que antecederam a publicação do Decreto $n^{\circ} 13.564 / 1927$ marcaram um período de grande instabilidade política na história portuguesa. A proclamação da República a 5 de outubro de 1910, capitaneada pelo Partido Republicano, depôs a Monarquia Constitucional e nomeou um governo provisório presidido por Teófilo Braga. Contudo, as disputas internas entre os republicanos e a eclosão da I Guerra Mundial desencadearam prolongada crise política. Após sucessivos golpes e renúncias de presidentes, o general Óscar Carmona tomou o poder a 9 de julho de 1926, instituindo uma ditadura militar até ser eleito Presidente da República no pleito de abril de 1928. Neste contexto surge, no governo, a figura de António de Oliveira Salazar como Ministro das Finanças. Quatro anos depois, ele ampliaria sua influência ao ser nomeado presidente do Conselho de Ministros.

A ditadura militar de 1926-28 inaugurou, assim, um período de estabilidade e marcou o início da organização de uma nova ordem que aponta para a lógica nacionalista estadonovista. De acordo com o historiador português Oliveira Marques (1991, p. 149), "seria errado, todavia, chamar fascista ao movimento militar de 1926. A rebelião fizera-se contra a ‘corrupção' e a 'degradação' da República Parlamentar”. Contudo, o desdobramento da

\footnotetext{
${ }_{3}^{3}$ Disponíveis na página eletrônica: Diário da República Eletrónico (Portugal): http://dre.pt/. Acesso em: 26 jul. 2013.

${ }^{4}$ Disponível na página eletrônica do Museu do Fado: www.museudofado.pt. Acesso em: 26 jul. 2013.
} 
ditadura em regime democrático a partir de 1928, acena com discurso de cunho nacionalista. Conforme relata Oliveira Marques, no outono de 1929,

Salazar caracterizou a futura reorganização constitucional como devendo basear-se 'em nacionalismo sólido, prudente, conciliador, salientou o papel a desempenhar pela família, a corporação moral e econômica, a freguesia e o município, e pronunciou o slogan que se tornaria famoso: 'Nada contra a nação, tudo pela Nação' (MARQUES, 1991, p. 149, grifos do autor).

É, portanto, no interior de uma lógica como a exposta, que o Decreto $n^{\circ}$. 13.564/1927 deve ser compreendido. Nesse sentido, destaca-se o estabelecimento da censura prévia aos espetáculos, realizada através da inspeção dos cartazes e dos programas pela Inspeção Geral dos Teatros, previsto no Art. $139^{\circ}$ do referido Decreto. Observa-se, assim, a partir do período da ditadura dos anos 1926-1928, a adequação da sociedade, e, portanto, da esfera da cultura, aos pressupostos de uma política de ordenamento aos interesses da nação, tal qual definido no relato de Salazar.

\subsection{Bem dentro d'alma. O Fado, de degenerado à canção nacional}

De acordo com Nery (2004), a origem do fado remonta ao início da segunda metade do século XIX ligada à imagem mítica de Maria Severa, prostituta, cantadeira e guitarrista falecida em novembro de 1846. Originalmente restrito às tabernas e aos bordéis localizados nos bairros populares da periferia de Lisboa, o fado começa, a partir dos anos 1860, a ganhar espaço entre outras camadas da sociedade lisboeta e até mesmo entre a intelectualidade coimbrã ${ }^{5}$. Contudo, até a década de 1870 , os fadistas de destaque são ainda prostitutas e rufiões sem profissão, situação que se modifica na década seguinte, quando trabalhadores assalariados surgem como fadistas de renome e o fado passa a circular entre outras camadas da sociedade.

Esta suposta ascensão social observada no universo fadista durante o último terço do século XIX parece estar na origem da crítica ao fado formulada pela chamada Geração de

\footnotetext{
${ }^{5}$ Há uma diferença entre o fado de Lisboa, dito "vadio", e o de Coimbra, chamado "canção", que não será abordada no presente trabalho.
} 
$1870^{6}$, grupo de intelectuais responsável por elaborar uma visão crítica da história de Portugal. Entre eles, destaca-se o literato Eça de Queiroz, o qual ridiculariza o fado em dois romances clássicos da literatura portuguesa. Em O Primo Basílio, lançado em 1878, o fado está relacionado com os sentimentos adúlteros e depravados da personagem Luisa. Nesta obra, o gênero é, por inúmeras vezes, associado a devaneios lascivos das mulheres. Em $A$ Ilustre Casa de Ramirez, de 1900, o autor descreve pejorativamente o fado como "rico em ais", associando-o a Videirinha, personagem bajulador e ignorante. De acordo com Carvalho (1983, p. 53), o literato português teria declarado na Gazeta de Portugal de 13 de outubro de 1867:

Atenas produziu a escultura, Roma fez o direito, Paris inventou a revolução, a Alemanha achou o misticismo. Lisboa que criou? O Fado... Fatum era um Deus no Olimpo; nestes bairros é uma comédia. Tem uma orquestra de guitarras e uma iluminação de cigarros. [...] A cena final é no hospital e na enxovia. O plano de fundo é uma mortalha.

A Geração de 1870 denunciou o sentimento português de decadência presente na segunda metade do século XIX, o qual foi reforçado em função do Ultimatum britânico de 1890 que exigia a renúncia de territórios coloniais no contexto da partilha do continente africano. A declaração de Eça de Queiroz à imprensa portuguesa, não obstante critique o fado pontualmente, ilustra, de maneira geral, o tom do discurso dos intelectuais dessa geração que, com olhos na antiguidade clássica e em Paris e Berlim, apela à modernização, impedida, segundo eles, pelo absolutismo monárquico, pela influência do catolicismo e do "espírito tridentino e escolástico que tinha bloqueado o progresso da ciência" (CATROGA, 1996, p. 159). Desde esse ponto de vista, buscava-se emplacar um novo pensamento na opinião púbica. Nery (2004) acrescenta, ainda, a influência, em curso no último terço do século XIX, do movimento folclorista romântico. Nesse contexto, investigadores como Teófilo Braga, buscavam inventariar o "patrimônio poético-musical da tradição rural portuguesa" (2004, p. 142) como único capaz de representar o povo. Assim, o fado, gênero musical urbano considerado recente e originário de degenerados sociais, não poderia prestar-se nem aos anseios de regeneração, nem tampouco a símbolo da nacionalidade.

No início do século XX, observa-se uma modificação no tratamento ao fado e no meio fadista. Nos primeiros anos surgem publicações dedicadas a compilar a história do fado ${ }^{7}$,

\footnotetext{
${ }^{6}$ Os principais nomes são: Antero de Quental, Eça de Queiroz, Oliveira Martins e Teófilo Braga.

7 Trata-se de: Carvalho (1982 [1903]) e Pimentel (1904). Numa espécie de prefácio à obra de Carvalho (1982), Joaquim Pais de Brito (1982) realiza um apanhado de obras publicadas acerca do fado. De acordo com ele, Pimental (1904) foi o primeiro a realizar uma classificação de temas concernentes ao gênero. Contudo, é a obra de Pinto de Carvalho (1982), vulgo Tinop, que Brito (1982) define como a melhor caracterização do ambiente
} 
considerando-o, desde então, manifestação inexorável da alma portuguesa. Em História do Fado, de Pinto de Carvalho (1983), publicada em 1903, o autor afirma: "no fado, - a mais sugestiva canção lusitana - revela-se a alma nacional palpitante de emoção" (1983, p. 287, grifos do autor). O novo tratamento dispensado ao fado nessas obras coincide com os reflexos, no plano sociopolítico, do florescimento de um nacionalismo exacerbado em decorrência do Ultimatum. Observa-se, então, sob a influência do romantismo alemão, um movimento de interiorização em busca de definir a nação através de características que pudessem traduzir uma cultura genuinamente portuguesa (CATROGA; CARVALHO, 1996; LOURENÇO, 1999).

A partir das duas primeiras décadas do século $\mathrm{XX}$, o cenário fadista também se modifica. Observa-se, então, uma profusão de publicações periódicas em defesa do fado, considerando-o canção nacional, dentre as quais, destaca-se a série de artigos intitulada $O$ fado e os seus censores, publicada em 1912 por Avelino de Sousa (1912). No início da obra o autor deixa claro sua intenção: "arvoro-me advogado de defeza do Fado... e creio que hei de salva-lo da furia médico-crítica dos seus censores" (SOUSA, 1912, p. 1, grifos do autor) ${ }^{8}$. Na década seguinte, destacam-se dois importantes jornais: Guitarra de Portugal ${ }^{9}$, lançado em 1922, utilizado como fonte neste trabalho, e Canção do Sul, lançado em 1923. Assiste-se, ainda, nesse período, à proliferação de novos espaços de atuação do fado, modificação

social relativo ao fado, além de destacar o caráter de pesquisa da obra, realizada com base em documentos e memórias, próprias e de terceiros. Tinop também é autor de obra que reúne artigos publicados na imprensa lisboeta. Intitulada Lisboa D'Outros Tempos, foi publicada em dois volumes: o primeiro data de 1898, tem por subtítulo Figuras e scenas antigas, e traz dois artigos dedicados especificamente ao Fado; o segundo, de 1899, subintitulado Os Cafés, faz menção ao fado. Nas Notas explicativas, texto que abre o primeiro volume, o autor assume seu perfil de pesquisador ao revelar que as informações de que dispõe foram coletadas através de recolha de memórias, de pesquisa na Biblioteca Nacional de Lisboa e nos arquivos da antiga Intendência Geral de Policia guardados no arquivo da Torre do Tombo, além de outros documentos e publicações.

${ }^{8}$ Os artigos constituem resposta às críticas publicadas por dois autores - Dr. Felix e Albino Forjaz de Sampaio no jornal $O$ Século. Com um tom militante, utilizando-se de linguagem alusiva ao operariado - Brito (1982) o define como anarquista numa espécie de prefácio à História do Fado de Pinto de Carvalho (1982) -, o autor posiciona-se em defesa do status de canção nacional atribuído ao fado e o define como "trova de propaganda social" (SOUSA, 1912, p. 35) capaz de contribuir para a instrução do povo. Para além dos atributos sociais, destaca ainda a capacidade dos poetas e trovadores de sentir "bem dentro d'alma toda a psychologia da velha canção e quanto ella está arreigada no animo do povo" (1912, p. 4).

9 Na primeira edição de Guitarra de Portugal, publicada a 15 de julho de 1922, matéria intitulada Nosso aparecimento desempenha papel de editorial. Assinada por um certo D. Serpa afirma: "Vimos contar aos novos o que foi toda a legião de trovadores obscuros publicando-lhe muitos dos seus trabalhados e abraçar todos os que queiram colaborar comnosco em prol da mais linda canção da nossa terra, pondo assim no sacrossanto altar dos costumes populares, dignificada e abençoada a Guitarra de Portugal" (1922, p. 1). Nesses termos, o texto revela, assim, um desejo de salvaguardar a memória do fado, transmitindo-o às novas gerações, além de atribuir ao gênero uma posição sacralizada, por assim dizer, enquanto símbolo nacional. O poeta e articulador do meio fadista, João Linhares Barbosa, assina como editor do jornal. Segundo Nery (2004), Linhares vê a entrada do fado em espaços diversos da sociedade (cafés, teatros, salas de espetáculo) como reconhecimento e consagração da cultural popular lisboeta. Ainda que procure assegurar um conjunto de parâmetros capazes de preservar a originalidade fadista, o editor fará de Guitarra de Portugal uma voz em defesa da expansão do fado a novos espaços (NERY, 2004). 
decisiva para deflagrar um processo de profissionalização do fadista. O fado passa, então, a ocupar cafés, cervejarias, salões de dança, teatros, sociedades de instrução, recreios, locais onde se pode ouvir o fado em ambiente que apresenta padrões estéticos capazes de atrair um público seleto. As páginas de Guitarra de Portugal e os cartazes utilizados como fonte revelam grande quantidade desses espaços: A Voz do Operário, Cervejaria Jansen, Coliseu de Coimbra, Floresta do Arco do Cego, Café dos Anjos, Cervejaria S. Paulo, Club Olímpia, Sul América, Café Luso, Avenida Bar ${ }^{10}$. De acordo com Nery (2004), na medida em que esses locais passam a apresentar programação regular, os artistas começam a receber pelo seu trabalho. A novidade introduzida pelo pagamento de cachês contrasta com o cenário dos primeiros anos do século XX, quando o fadista é definindo como "alguém que ainda tem, de um modo geral, outra profissão, e que em muitas das suas prestações artísticas de carácter mais informal não é remunerado" (2004, p. 137). Avelino de Sousa, citado anteriormente, serve de exemplo ao assumir-se "de profissão compositor typographico, e , nas horas vagas... Fadista (com F. de caixa alta)" (SOUSA, 1912, p. 2, grifos do autor).

No final da década de 1920, assiste-se à institucionalização da profissionalização do fadista através do já mencionado Decreto $\mathrm{n}^{\circ}$. 13.564/1927. O processo estava em curso, contudo, desde a ampliação dos espaços de atuação do fado e do surgimento de uma nova geração de fadistas profissionais - Berta Cardoso, Hermínia Silva, Ercília Costa e Alberto Costa são os nomes que mais aparecem nas páginas de Guitarra de Portugal -, os quais vão consolidar o fado inclusive internacionalmente. De acordo com Nery (2004), as exigências legais de adaptação dos espaços artísticos, definidas pelo decreto mencionado, fizeram surgir a ideia da criação de locais exclusivos. Trata-se das "Casas de Fado". Conta o autor que a pioneira foi o Solar da Alegria, inaugurada em 1928 e reinaugurada em 1931 após período de interrupção das atividades. Guitarra de Portugal, por ocasião da reinauguração, dedica matéria especial na edição de 6 de fevereiro de 1931: “cicatrizaram-se as cavernas do pulmão doente e o fado, o trovador genial da nossa querida Lisboa, vai respirar a plenos pulmões: vai abrir o Solar da Alegria" (1931, p. 7). Na edição de 18 de abril de 1931, a "casa" já é tratada como "o maior templo do Fado" (1931, p. 7). Ainda segundo Nery (2004), em espaços como o Solar, buscava-se dignificar o gênero, o qual gozava então do status simbólico-identitário de canção nacional: "a regra fundamental é a do silêncio absoluto durante a execução ("Silêncio que se vai cantar o Fado" é a recomendação que mais frequentemente se lê em inscrições na parede ou se ouve anunciar a um eventual apresentador)" (Nery, 2004, p. 198, grifos do

\footnotetext{
${ }^{10} \mathrm{O}$ curto espaço de que se dispõe neste trabalho torna inviável listar todos os locais, de forma que somente é possível citar alguns.
} 
autor). Como mais um elemento desse processo de dignificação, modificam-se os figurinos: os homens vestem terno escuro e as mulheres xale preto.

O Fado conquistou nestes locais um espaço de apresentação privilegiado onde procura o aplauso de franjas distintas da sociedade, e deve por isso dar de si mesmo uma imagem solene, hierática, ritual, reivindicando uma função de corporização nuclear da própria identidade nacional e excluindo por completo qualquer aproximação aos traços de marginalidade que desde sempre lhe foram apontados pelos seus inimigos (NERY, 2004, p. 198).

O Decreto $n^{\circ}$. 13.564/1927 traz ainda outros condicionantes à poesia e ao meio fadista. De acordo com Brito (1999), na medida em que se introduziu a censura aos poemas e aos locais onde os artistas do fado se apresentavam, engessou-se não só o repertório, mas também a forma de expressão típica do gênero, o improviso. Nery (2004), por sua vez, destaca a obrigatoriedade de registro e licenciamento das letras, atribuindo-as autoria e deflagrando a lógica de comercialização de composições. Conta o autor que, neste contexto, a fadista Berta Cardoso passou a pagar pelas letras que cantava, atraindo os melhores poetas do meio.

Também o desenvolvimento da indústria fonográfica e do sistema de radiodifusão, os quais ocorrem paralelamente à proliferação dos espaços dedicados ao fado, impuseram modificações. Embora incipientes durante o período abordado neste trabalho, desempenharam papel de divulgação do gênero ao restante do país e ao exterior. Ambos, o disco e o rádio, influenciaram diretamente o repertório fadista. O primeiro porque condicionou a extensão do poema, agora submetido ao limite de gravação de cada disco; o segundo porque, através de critérios de seleção de fadistas, repertórios e vozes, definiu novos padrões estéticos e estilísticos (NERY, 2004; BRITO, 1999).

Divulgado, então, pelo disco e pela rádio, o fado expande seus territórios de atuação. Surgem, então, as troupes, companhias de fadistas profissionais que saem em turnê pela Europa e pelo mundo. Eventualmente, formam-se também as chamadas "embaixadas" de fado, companhias esporádicas constituídas para viagens específicas (NERY, 2004). Guitarra de Portugal dá publicidade às turnês com um tom de divulgação do caráter identitário que se queria atribuir ao fado. Na edição de 18 de setembro de 1932 traz matéria intitulada "Do Brasil", noticiando o retorno a Lisboa, no dia 13 do mesmo mês, da Companhia Estevam Amarante. Referindo-se à fadista Maria Alice como "embaixatriz do Fado", relata que a artista "vem cheia de satisfação pela forma como foi acolhida por todos os nossos compatriotas que no Brasil vivem, bem como da maior parte dos brasileiros que não sabiam 
esconder o encanto que o Fado lhes dava" (1932, p. 6). Por meio dessas viagens, a nação portuguesa é, então, levada ao mundo através do fado enquanto canção nacional.

Conforme se demonstrou, desde o início do século XX, o fado vem consolidando-se como canção nacional. Em 30 de abril de 1929, Guitarra de Portugal publicou a introdução de uma obra literária intitulada “Alma de fadista”, de autoria de Venceslau D’Oliveira, a qual, segundo a matéria, fazia sucesso nos meios fadistas de então. Nela pode-se observar a percepção de um contemporâneo acerca do processo de afirmação do gênero enquanto canção nacional:

Fica, pois, quebrada a lenda acalentada pela detractação canalha de que " $o$ Fado foi sempre uma canção de degenerados, andando só, de começo, na boca de rameiras e rufias que dedilhavam guitarras com tanta agilidade como manejavam a navalha"; - o Fado, para honra de todos os fadistas, hoje [como] ontem, entrou nos mais nobres salões pela mão duma plêiade de ilustres fidalgos, e jamais renegou o cognome - aliás justo, por andar na alma de todos os portugueses - de CANÇÃO NACIONAL (1929, p. 6, grifos do autor).

\section{Uma cultura comum. O imaginário do Fado como canção da alma nacional}

Pode-se afirmar agora que, no período abordado neste trabalho, a nação portuguesa dispunha de um imaginário do fado como canção nacional, proporcionado por uma diversidade de meios e atores sociais. Seja em obras elaboradas por intelectuais, como Carvalho (1983) e Pimentel (1904), artigos de militantes, como os publicados por Sousa (1912), ou através das páginas de jornais como Guitarra de Portugal, o fado foi sendo difundido como manifestação da alma portuguesa, proporcionando, assim, que a nação se imaginasse através e em forma de fado ${ }^{11}$.

O historiador português Fernando Catroga (2005) retoma a ideia da nação imaginada, legitimando-a através da utilização do conceito de religião civil, tomado de Rousseau, cuja “função reside na sacralização do viver comum de uma dada coletividade" (2005, p. 12). Dessa forma, entende a nação como uma comunidade que desempenha tarefas cognitivas e afetivas: a primeira "fornece visões globais e totalizantes acerca da origem, evolução e

\footnotetext{
${ }^{11}$ Nesses termos, Benedict Anderson (2008), segundo uma perspectiva antropológica, define a nação como comunidade imaginada. Segundo o autor, o conceito de nação deve ser tratado como objeto cultural historicamente datado no final do século XVIII e da mesma forma como se trata a religião ou o parentesco, devido à impossibilidade de pensá-lo como manifestação racional. Na tentativa de traçar as origens da consciência nacional, o autor define o capitalismo de imprensa como principal elemento da possibilidade de se imaginar a nação, já que introduz uma ideia de simultaneidade entre os membros de uma mesma comunidade através da difusão de publicações em vernáculo. Quanto a esse último aspecto, acredita-se que o conjunto de fontes utilizado neste trabalho, sobretudo Guitarra de Portugal, desempenha papel como elementos que possibilitaram o imaginário do fado como canção nacional.
} 
destino do universo e do homem"; a segunda considera que "a sacralidade que lhe é inerente manifesta-se em símbolos, ritos, gestos e atitudes" (2005, p. 10). Seguindo essa lógica, a ideia de nação portuguesa no estudo do fado contém, de um lado, aquela perspectiva de futuro, de destino, mencionada na introdução; de outro, elementos simbólicos que fazem com que os membros de uma comunidade identifiquem-se entre si, ainda que sem conhecerem-se.

Quanto à primeira tarefa, a nação entende-se, simultaneamente, como resultado de um processo histórico e como um projeto ideal de futuro que visa à permanência. De acordo com o historiador alemão Reinhart Koselleck (2006), as categorias de "campo de experiência" e "horizonte de expectativa" podem dar conta das experiências vividas e das expectativas das pessoas, na medida em que entrelaçam as noções de passado e futuro, sentidas ou elaboradas no presente, baseadas tanto em pressupostos racionais quanto em formas inconscientes de comportamento. Em outras palavras, trata-se de considerar a experiência como "passado atual, aquele no qual acontecimentos foram incorporados e podem ser lembrados" (2006, p. 309), e a expectativa como "futuro presente, voltado para o ainda-não, para o não experimentado, para o que apenas pode ser previsto" (2006, p. 309). Essa parece ser a visão do fado presente nas fontes utilizadas - Carvalho (1983), Pimentel (1904), Sousa (1912) e Guitarra de Portugal (1922-1933), na medida em que o elegem como canção nacional, ou seja, como uma realidade atual e, ao mesmo tempo, como projeto de futuro assegurado pela carga simbólica e identitária atribuída ao gênero. Essa visão parece explicar também a lacuna historiográfica, identificada na introdução, concernente a ausência de análises do fado em obras sobre cultura em Portugal. É que o futuro projetado desde o presente não necessariamente se efetiva de maneira absoluta, já que nem todos os membros da nação endossam o ideal elaborado no passado. Koselleck (2006) reforça essa ideia: "sempre as coisas podem acontecer diferentemente do que se espera: esta é apenas uma formulação subjetiva daquele resultado objetivo, de que o futuro histórico nunca é o resultado puro e simples do passado histórico" (2006, p. 312); do contrário, a possibilidade de a ação humana transformar a realidade estaria excluída.

Ainda concernente às tarefas cognitivas desempenhadas pela nação, a ideia de destino ocupa papel de suma importância no entendimento que os portugueses possuem de si e que o fado, e os fadistas, parecem traduzir. O historiador português Eduardo Lourenço, no ensaio Portugal como Destino (1999), elabora de forma eloquente uma noção de futuro que se pode relacionar com a de Koselleck (2006): "antes da plena consciência de um destino particular aquela que a memória, como crónica ou história propriamente dita, revisita -, um povo é já um futuro e vive do futuro que imagina para existir" (LOURENÇO, 1999, p. 10). Sua noção 
de destino assenta-se, assim, igualmente naquela ideia de entrelaçamento entre passado e futuro, abordando de forma subliminar o entendimento que um povo possui de si e daquilo que pretende ser. A declaração do fadista Alberto Costa, em matéria da edição de Guitarra de Portugal de 4 de julho de 1932, ilustra essa ideia ao fundir o fado a sua própria existência: "Fado! Destino... sinónimo da minha sina"12. É como se, baseado num entendimento imanente, o porvir pudesse ser vislumbrado com clareza. Tal noção aqui esboçada guarda relação com a herança de um ideário romântico na visão do fado como alma nacional, matéria abordada a seguir, quando da discussão em torno do conceito de identidade nacional.

A segunda tarefa desempenhada pela nação, definida por Catroga (2005) como afetiva, refere-se ao apelo emocional. É identificada, no caso deste estudo, na própria ideia da alma portuguesa transfigurada em fado enquanto poesia popular toda vez que se senta para ouvi-lo. Neste aspecto, as transformações em curso durante o período identificado no final da década de 1920, em função da publicação do Decreto $\mathrm{n}^{\circ}$. 13.564/1927 e materializadas no novo comportamento observado nos novos espaços, ilustram um desejo de ritualização nas práticas artísticas do fado que objetivava dignificar o gênero mediante as diversas camadas da sociedade. Nesse sentido, seguindo o pensamento de Catroga (2005, p. 11), passa-se a observar um "halo de sacralidade" não só na ritualização das apresentações dos artistas, como também no tratamento dispensado ao fado enquanto símbolo da nação, presente, sobretudo, no emblemático apelo "Silêncio que se vai cantar o fado" (NERY, 2004, p. 199) ${ }^{13}$. Assim, a nação portuguesa, em suas mais diversas camadas sociais, dispõe de um imaginário do fado como símbolo nacional, graças a um novo conjunto de práticas responsáveis por atribuir novos padrões estéticos e morais ao gênero, num esforço de conectá-lo a um passado não

\footnotetext{
${ }^{12}$ COSTA, Alberto. "Um grande cantador". Guitarra de Portugal, 4 de julho de 1932, p. 1.

${ }^{13}$ Conforme se demonstrou, a tentativa de dignificar o gênero através da ritualização das práticas fadistas tratou de modificar alguns padrões e inventar outros. Em A Invenção das Tradições, o historiador Eric Hobsbawm (2008) defende que os símbolos nacionais são inventados de acordo com princípios e necessidades de cada nação (não se está considerando aqui a perspectiva marxista do autor de considerar a ligação das tradições inventadas com o passado de maneira artificial, já que se considera o processo de modificação ou invenção de padrões ligados ao fado como decorrentes de necessidades e da percepção dos meios fadistas). É dessa forma que surge o que denomina de tradição inventada, entendida como "um conjunto de práticas, normalmente reguladas por regra tácita ou abertamente aceitas; tais práticas, de natureza ritual ou simbólica, visam inculcar certos valores e normas de comportamento através da repetição, o que implica, automaticamente, uma continuidade em relação ao passado" (2008, p. 9). Conforme o autor, tais invenções ocorrem, com frequência, em contextos de transformações da sociedade. No caso das modificações efetivadas com intuito de dignificar o fado, observa-se ocorrerem num período em que o país enfrenta, no esteio da ditadura militar de 1926-1928, o início do processo de organização de uma nova ordem que aponta para a lógica nacionalista estadonovista, submetendo todos os níveis da sociedade aos interesses de um estado corporativo. É desse contexto de reinvenção da nação a publicação do Decreto $n^{\circ}$. 13.564/1927, responsável por deflagrar as ditas modificações dignificantes no gênero e no cenário fadista, que assistia à diversificação social do seu público espectador. Tais modificações podem ser enquadradas no terceiro tipo de tradição inventada elaborada pelo autor: "aquelas cujo propósito principal é a socialização, a inculcação de idéias, sistemas de valores e padrões de comportamento" (2008, p. 17).
} 
mais relacionado com os meios marginalizados. A partir de então, o fado parece atingir um conjunto de características que o torna passível de se tornar uma cultura comum (SMITH, 1997), demonstrando, portanto, condições de figurar como identidade nacional.

Conforme exposto, a nação foi abordada aqui como uma abstração delineada por um conjunto de valores históricos e culturais, pré-existentes ou não, a partir dos quais a comunidade imagina-se, criando uma identidade. A discussão em torno da identidade nacional sustenta-se, neste trabalho, numa perspectiva etno-simbolista (SMITH, 1997), através da utilização do conceito de identidade étnica ${ }^{14}$, a qual adquire sentido através de um conjunto de atributos histórico e simbólico-culturais. As características identificadas no fado enquadramse em tal perspectiva na medida em que se retomam aquelas questões envolvidas na discussão acerca das tarefas cognitivas e afetivas desempenhadas pela nação no estudo do fado: a noção de futuro, e de destino, e a carga simbólico-identitária atribuída ao gênero através da ritualização como tentativa de dignificação.

Dentre os atributos definidos por Smith (1997) como componentes da identidade étnica, tem importância, para este trabalho, o que denomina de "um ou mais elementos diferenciadores de cultura comum" (1997, p. 37). Assim, torna-se chave para compreender a ideia de identidade nacional portuguesa no estudo em questão, o entendimento do fado como “poesia popular", assim definido em matéria dedicada à fadista Hermínia Silva na edição de Guitarra de Portugal de 30 de novembro de $1932^{15}$.

Desde os primeiros anos do século XX, conforme mencionado anteriormente, o fado surge como manifestação da alma portuguesa, expressão que carrega a ideia de espírito ou caráter nacional presente na tradição filosófica acerca do conceito de nação ${ }^{16}$. Percebe-se, portanto, uma herança romântica nessa referência. O romantismo alemão destacou o papel central da língua na constituição das nações. Johann Gottfried Herder (1959), um dos maiores expoentes do movimento, definiu, em 1784, que "en cada uno de los idiomas están expressados el carácter y el intelecto de um pueblo" (1959, p. 272). A língua proporcionaria,

\footnotetext{
${ }^{14}$ Anthony D. Smith (1997) utiliza o conceito de "etnia" como sinônimo de coletividade cultural de caráter histórico, já que considera essenciais as memórias históricas e as forças históricas específicas responsáveis pela produção de cada um dos grupos étnicos. Sua perspectiva situa-se entre aquelas que atribuem ao conceito de etnicismo uma qualidade "primordial", ligado à natureza, e aquelas que o consideram "situacional", ou seja, que se modificam conforme a situação do indivíduo. A abordagem coloca-se, assim, em oposição ao conceito de "raça", definido como "um grupo social que se considera possuir traços biológicos únicos que determinam pretensamente os atributos mentais do grupo", utilizado pelos discursos e ideologias racistas pretensamente científicos entre os anos de 1850 e 1945 (1997, p. 37).

${ }^{15}$ Guitarra de Portugal, 30 de novembro de 1932, p. 1.

${ }^{16}$ De acordo com Llobera (2000), embora tal ideia retome ao século XVIII, através dos trabalhos de pensadores como Montesquieu e Hume, que se dedicaram a explicar a sociedade, Rousseau ocupa o papel de grande teórico político da ideia de nação moderna, enquanto Herder é definido pelo autor como o fundador do nacionalismo cultural. Interessa-nos aqui, o ponto de vista cultural.
} 
segundo o autor, uma historia em formas herdadas pela alma e pelo coração. Johann Gottlieb Fichte (2009), por sua vez, defendeu, em 1808, que a língua "é o verdadeiro ponto de confluência do mundo dos sentidos e [...] dos espíritos e que funde o termo destes dois um no outro" (2009, p. 114). Assim, ao evidenciar o papel da língua como instrumento de divulgação das características de um povo, o romantismo pôs em evidencia a figura do artista, sobretudo do poeta, considerado capaz de sintetizar e manifestar o pensamento da nação ${ }^{17}$. Seguindo essa lógica, Fichte (2009) define a poesia como o meio mais eficaz de introduzir um pensamento na sociedade, "o mais excelente meio de espalhar a formação espiritual alcançada na vida geral" (2009, p. 124).

Com isso, quer se vincular a imagem do poeta idealizado pelo romantismo alemão à figura do fadista e a do próprio fado à cultura popular em geral e à poesia popular em particular. A cultura popular ocupa lugar de destaque na conformação identitária, na medida em que, sendo depositária da herança de um povo, serve de fundamento da cultura nacional ${ }^{18}$. Bem vistas as coisas, o gênero pode ser considerado canção popular devido a sua origem mítica, ligada à figura de Maria Severa, e manifestação espontânea, características que tornam difícil uma apreensão genealógica. Sem conservatórios dedicados a compilar seu conhecimento e com espaço restrito entre os intelectuais e artistas vinculados à música erudita, o fado surge e se desenvolve de maneira autônoma num primeiro momento, sem uma sistematização dos conhecimentos inerentes a sua produção. Se procurarmos delimitar esse momento, é possível afirmar que a canção popular:

está muito mais próxima dos setores menos escolarizados (como criador e receptor), que a maneja de modo informal [...] e cria uma sonorização muito própria e especial que acompanha sua trajetória e experiências. Além disso, a canção é uma expressão artística que contém um forte poder de comunicação, principalmente quando se difunde pelo universo urbano, alcançando ampla dimensão da realidade social (MORAES, 2000, p. 204) ${ }^{19}$.

Retoma-se assim, aquele atributo característico da identidade étnica, anteriormente destacado. A imagem do fado entendido como canção popular com status de canção nacional

\footnotetext{
${ }^{17}$ Segundo o pensamento romântico, o poeta desempenha papel análogo ao do filósofo na tradição iluminista, De acordo com Franklin Baumer, o artista "se tornou o homem ideal do Mundo Romântico, substituindo o philosophe” (1977, p. 40, grifos do autor).

${ }^{18}$ Cf. Thiesse, A-M (2001/2002).

${ }^{19}$ É preciso ter claro que tal entendimento de canção popular está restrito a um período específico. Conforme se evidenciou neste artigo, o fado passa, no início do século XX, a gozar de outro status.
} 
o credencia como cultura comum caracterizada como alma e destino do povo português, e, por consequência, como identidade lusa.

\section{Considerações finais}

$\mathrm{Na}$ apresentação deste artigo, mencionou-se que o desenvolvimento da pesquisa havia ampliado a noção da falta de consenso quanto ao status de canção nacional de que gozou, e que goza atualmente, o fado. Embora neste artigo tenha se optado por utilizar, com exceção de Eça de Queiroz, fontes nas quais se procede à defesa do fado, procurou-se demonstrar que os seus autores e atores possuíam interlocutores por vezes acusados de detratores da canção nacional. Sem dúvida essa situação denuncia falta de unanimidade.

De maior relevância, considera-se que a pesquisa tem colocado em evidência a relação entre o fado e uma espécie de comportamento atribuído aos portugueses, revelando uma visão do gênero musical sob forte influência do ideário romântico assente na ideia de espírito ou caráter nacional. Dessa forma, baseado principalmente no jornal Guitarra de Portugal, constatou-se um retrato do fado como alma e destino do povo português, enquanto expressão popular com status de canção nacional capaz de credenciá-lo como uma cultura comum. Trata-se da imagem, que a eloquência de Eduardo Lourenço (1999) é capaz de compor, do povo que “canta ‘o fado' ou no fado se canta” (1999, p. 43). Como prosopopeia, é como se o gênero musical constituísse ele próprio a personalidade lusitana, a índole nacional.

\section{REFERÊNCIAS BIBLIOGRÁFICAS}

ANDERSON, B. Comunidades imaginadas: reflexões sobre a origem e a difusão do nacionalismo. São Paulo: Companhia das Letras, 2008.

BAUMER, F. L. O Pensamento Europeu Moderno. Volume II, Séculos XIX e XX. Lisboa: Edições 70, 1990.

BRITO, J. P. de. "O fado: etnografia na cidade”. In: VELHO, G. (org.). Antropologia urbana: cultura e sociedade no Brasil e em Portugal. Rio de Janeiro: Zahar, 1999, p. 24-42.

. "Sobre o fado e a História do Fado". In: CARVALHO, P. de. História do

Fado. Lisboa: Publicações Dom Quixote, 1982. 
CATROGA, F. Nação, mito e rito: religião civil e comemoracionismo (EUA, França e Portugal). Fortaleza: Edições NUDOC / Museu do Ceará, 2005.

CATROGA, F; CARVAlHO, P. A. de. Sociedade e Cultura Portuguesas II. Lisboa: Universidade Aberta, 1996.

FICHTE, J. G. Discursos à Nação Alemã. Lisboa: Círculo de leitores, 2009.

GASPAROTTO, L. A. "Silêncio que se vai cantar o Fado": a identidade nacional portuguesa no processo de profissionalização do fadista (1927 - 1933). In: IX Congresso Internacional de Estudos Ibero-Americanos - IX CIEIA, 2013, Porto Alegre. Anais eletrônicos. Porto Alegre: PUCRS, [no prelo].

HERDER, J. G. Ideas para una filosofia de la humanidad. Buenos Aires: Editorial Losada, 1959.

HOBSBAWM, E. J. "Introdução: a invenção das tradições". In: HOBSBAWM, E. J.; RANGER, T. A invenção das tradições. Rio de Janeiro: Paz e Terra, 2008.

KOSELLECK, R. Futuro passado: contribuição à semântica dos tempos históricos. Rio de Janeiro: Contraponto: Ed. PUC-Rio, 2006.

LLOBERA, J. R. O Deus da Moderindade: o desenvolvimento do nacionalismo na Europa Ocidental. Oeiras: Celta Editora, 2000.

LOURENÇO, E. Portugal como Destino seguido de Mitologia da Saudade. Lisboa: Gradiva, 1999.

MARQUES, A. H. de Oliveira. História de Portugal. Lisboa: Imprensa Nacional-Casa da Moeda, 1991.

MORAES, J. G. V. História e música: canção popular e conhecimento histórico. Revista Brasileira de História. São Paulo, v. 20, n. 39, p. 203-221, 2000.

NERY, R. V. Para uma história do fado. Lisboa: Público: Corda Seca, 2004.

SARAIVA, A. J. A cultura em Portugal: teoria e história. Livro 1. Lisboa: Gradiva, 1994.

SMITH, A. D. Identidade Nacional. Lisboa: Gradiva, 1997.

THIESSE, A-M. Ficções criadoras: as identidades nacionais. Anos 90, Porto Alegre: UFRGS, n. $15,2001 / 2002$, p. $7-23$.

\section{FONTES}

Cartaz A Voz do Operário, Lisboa, 1930.

Cartaz Cervejaria Jansen, Lisboa, 1930.

Cartaz Coliseu de Coimbra, Coimbra, 1931. 
CARVALHO, P. de. História do Fado. Lisboa: Publicações Dom Quixote, 1982 [1903]. Lisboa D'Outros Tempos, v. 2: os cafés. Lisboa: Livraria de Antonio Maria Pereira, 1899.

. Lisboa D'Outros Tempos, v. 1: figuras e scenas antigas. Lisboa: Livraria de Antonio Maria Pereira, 1898.

Guitarra de Portugal, Lisboa, de 1927 a 1933 (edições descontínuas).

Guitarra de Portugal, Lisboa, 15 de julho de 1922.

Licença profissional de Sebastião Caetano Pires, Lisboa, 1939. Disponível em: www.museudofado.pt. Acesso em: 26 jul. 2013.

PIMENTEL, A. A Triste canção do Sul (subsídios para a história do fado). Lisboa: Livraria Central de Gomes de Carvalho, 1904.

PORTUGAL. Decreto n ${ }^{\circ}$ 13.564, de 6 de maio de 1927. Diário do Govêrno, Lisboa, 6 mai. 1927. I Série, n. 92, pp. 689-704. Disponível em: http://dre.pt/. Acesso em: 26 jul. 2013.

Constituição Política da República Portuguesa, de 22 de fevereiro de 1933. Diário do Govêrno, Lisboa, 22 fev. 1933. I Série, n. 43, pp. 227-236. Suplemento. Disponível em: http://dre.pt/. Acesso em: 26 jul. 2013.

QUEIROZ, E. de. O Primo Basílio. Rio de Janeiro: Edições de Ouro, [1878].

A Ilustre Casa de Ramires. São Paulo: Brasiliense, 1973 [1900].

SOUSA, A. de. O fado e os seus censores: artigos colligidos da Voz do Operario: critica aos detractores da canção nacional; com uma carta do illustre poeta e dramaturgo Dr. Julio Dantas. Lisboa: 1912.

ARTIGO ENVIADO EM:28/01/2014

ACEITO PARA PUBLICAÇÃO EM: 16/10/2014 